\title{
Evidence for pathogenicity of variant ATM Val1729Leu in a family with ataxia telangiectasia
}

\author{
Ali S. Shalash ${ }^{1}$ (1D - Thomas W. Rösler ${ }^{2,3} \cdot$ Mohamed Salama $^{4,5}$ (1) $\cdot$ Manuela Pendziwiat $^{6,7} \cdot$ Stefanie H. Müller $^{8}$. \\ Franziska Hopfner ${ }^{9}$ (D) - Günter U. Höglinger ${ }^{2,3,9}$ (D) $\cdot$ Gregor Kuhlenbäumer $^{10}(\mathbb{C}$
}

Received: 29 January 2021 / Accepted: 16 March 2021 / Published online: 29 March 2021

(C) The Author(s) 2021

\begin{abstract}
Ataxia telangiectasia is a rare autosomal recessive multisystem disorder caused by mutations in the gene of ATM serine/threonine kinase. It is characterized by neurodegeneration, leading to severe ataxia, immunodeficiency, increased cancer susceptibility, and telangiectasia. Here, we discovered a co-segregation of two ATM gene variants with ataxia telangiectasia in an Egyptian family. While one of these variants (NM_000051.4(ATM_i001):p.(Val128*)) has previously been reported as pathogenic, the other one (NM_000051.4(ATM_i001):p.(Val1729Leu)) is regarded as a variant of uncertain significance. Our findings in this family provide additional evidence for causality of the second variant and argue that its status should be changed to pathogenic.
\end{abstract}

Keywords Ataxia telangiectasia $\cdot$ ATM serine/threonine kinase $\cdot$ Mutation $\cdot$ Pathogenicity $\cdot$ Egypt

\section{Introduction}

The rare multisystem disorder ataxia telangiectasia (AT) usually starts in childhood and causes neurodegeneration leading to ataxia, movement disorders, and peripheral neuropathy [1]. Additional characteristics are variable amounts of immunodeficiency, increased susceptibility to cancer, especially of lymphoid origin, telangiectasia, and several additional symptoms [2]. AT is an autosomal recessive disorder known to be caused by variants in the ATM serine/threonine kinase gene (ATM) [3].

In the present study, we analyzed an Egyptian family with AT. The family consisted of non-consanguineous parents and four siblings; three of whom are affected by AT. The brother

Ali S. Shalash, Thomas W. Rösler, Günter U. Höglinger, and Gregor Kuhlenbäumer contributed equally.

Gregor Kuhlenbäumer

Gregor.Kuhlenbaeumer@uksh.de

1 Department of Neurology, Faculty of Medicine, Ain Shams University, Cairo, Egypt

2 Department of Neurology, School of Medicine, Technical University of Munich, Munich, Germany

3 Department of Translational Neurodegeneration, German Center for Neurodegenerative Diseases (DZNE), Munich, Germany

4 Institute of Global Health and Human Ecology, American University in Cairo (AUC), Cairo, Egypt and youngest sister had presented with ataxia, while another sister had a history of ataxia and died undiagnosed at the age of 6 years. We identified compound heterozygous, most likely causative variants in the ATM gene.

\section{Material and methods}

\section{Clinical phenotyping}

Ethical approval was obtained by Mansoura University, Egypt (RP/42), and Technical University of Munich, Germany (203/ $15 \mathrm{~s})$. Written informed consent was obtained for all

5 Faculty of Medicine, Mansoura University, Mansoura, Egypt

6 Institute of Clinical Molecular Biology, University of Kiel, Kiel, Germany

7 Department of Neuropediatrics, University Medical Center Schleswig-Holstein, University of Kiel, Kiel, Germany

8 Institute of Health Informatics, UCL, London, UK

9 Department of Neurology, Hannover Medical School, Hannover, Germany

10 Department of Neurology, University of Kiel, Kiel, Germany 
participants. If the participant was minor or incapable, consent was given by the legal custodian. Neurologists specialized in movement disorders (A.S.S. and G.U.H.) examined affected and unaffected individuals at the Department of Neurology, Ain Shams University, Cairo, Egypt. Affected individuals II:1 and II:4 were examined by standard cranial MRI at 1.5 Tesla with T1, T2, and FLAIR sequences.

\section{Genetic analysis}

Exome sequencing was performed in the two living, affected individuals II:1 and II:4. Genomic DNA libraries were captured using the Nextera Rapid Capture Expanded Exome Kit (Illumina, San Diego, CA), and DNA fragments were sequenced on an Illumina HiSeq2000 system with an average coverage of $80 \times$. Variants were identified by a standard analysis pipeline and annotated using the ANNOVAR software [4]. Since the parents are not known to be related, we assumed autosomal recessive inheritance and compound heterozygosity or homozygosity of the causative variant(s). We discarded the sex chromosomes and variants with a minor allele frequency $(\mathrm{MAF})>0.01$ in gnomAD (Genome Aggregation Database) "all" (https://gnomad.broadinstitute.org) exome as well as genome data. We discarded variants without an annotated exonic or splicing function and variants with a CADD score below 15 [5]. Next, we filtered for variants present in both exomes in the hetero- or homozygous state in the genes with the HUGO (Human Genome Organization) official symbols
ATM, MRE1, APTX, SETX, and PNKP implicated in the pathogenesis of AT and its differential diagnoses [2]. This resulted in two variants in the ATM gene which were confirmed and tested for segregation in the whole family by Sanger sequencing. Primer sequences are available on request. We detected no variants fulfilling the abovementioned criteria in any of the 4 other genes. The effects of amino acid substitutions on protein function were predicted using MutationTaster [6], PolyPhen-2 [7], and CADD. We searched the public version of the Human Gene Mutation Database [8], ClinVAr [9], and the Leiden ATM mutation database [10] for the identified variants.

\section{Results}

\section{Case reports}

The detailed clinical findings of both living patients are presented in Table 1, and the pedigree is shown in Fig. 1. Patient 1 (II:1) presented to us at age 23 with gait and limb ataxia, spastic paraparesis with pyramidal signs in the presence of length-dependent peripheral neuropathy. He showed dystonia of the upper limbs as well as the neck, severe dysarthria, oculomotor abnormalities, and cognitive impairment. At age 14, he developed focal seizures. Patient 2 (II:4) is a sister of patient 1 and presented to us at age 11 with a very similar clinical picture but with less prominent dystonia and without epileptic seizures. Both patients showed cerebellar atrophy on

Table 1 Clinical features of the AT patients

\begin{tabular}{|c|c|c|}
\hline Demographic/clinical features & Patient \#1 (II:1) & Patient \#2 (II:4) \\
\hline Age at onset (y) & 1.5 & 1.6 \\
\hline Age at first examination $(y)$ & 23 & 11 \\
\hline Age at last follow-up (y) & 27 & 14.5 \\
\hline Sex & Male & Female \\
\hline Eye movement abnormalities & Nystagmus, oculomotor apraxia & Nystagmus, oculomotor apraxia \\
\hline Bulbar abnormalities & Dysarthria & Dysarthria \\
\hline Upper motor neuron & Spastic paraparesis, pyramidal signs & Spastic paraparesis, pyramidal signs \\
\hline Lower motor neuron & $\begin{array}{l}\text { Absent ankle jerk, sensory loss, and wasting } \\
\text { of small foot muscles }\end{array}$ & $\begin{array}{l}\text { Absent ankle jerk, sensory loss, and wasting } \\
\text { of small foot muscles }\end{array}$ \\
\hline Movement disorders & Limb ataxia, dystonia of upper limbs and neck & Limb ataxia, chorea \\
\hline Age at wheelchair dependence (y) & 15 & 10 \\
\hline Epileptic seizures & Focal seizures & None \\
\hline Cognitive impairment & Moderate to severe & Moderate to severe \\
\hline Telangiectasia & Conjunctival & Conjunctival \\
\hline Skin changes & Few vitiligo-like patches & Prominent vitiligo-like \\
\hline Alpha-fetoprotein (AFP) & $\begin{array}{l}521 \mathrm{ng} / \mathrm{ml} \text { at age } 22 \\
\text { (strongly elevated) }\end{array}$ & $\begin{array}{l}457 \mathrm{ng} / \mathrm{ml} \text { at age } 10 \\
\text { (strongly elevated) }\end{array}$ \\
\hline Brain MRI & Cerebellar atrophy & Cerebellar atrophy \\
\hline
\end{tabular}




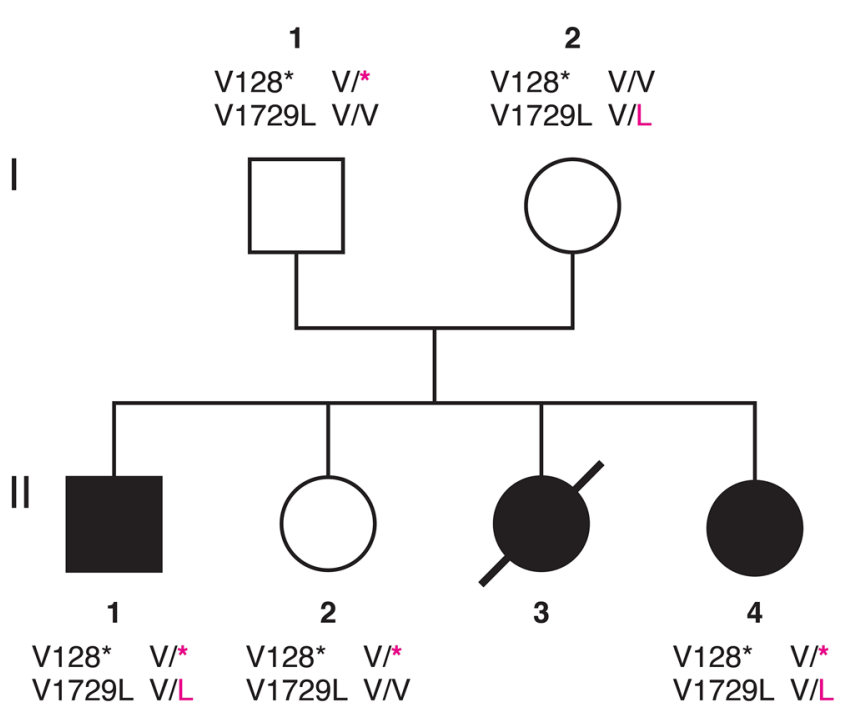

Fig. 1 Pedigree of the family with genotypes of variants 1 and 2. Square, male; circle, female; no filling, not affected; black filling, affected; slash, deceased. Exact HGVS nomenclature of variant 1 (V128*) and variant2 (V1729L) is shown in Table 2

cranial MRI. Both patients suffered from recurrent infections and showed conjunctival telangiectasia (Fig. 2a, b) as well as hypopigmented skin patches. Progressive ataxic gait noticed at the age of around 1.5 years was the first symptom in both siblings. Increased levels of alpha-fetoprotein (AFP) were found in both affected siblings. Another sister (II:3) died at age 6 with a similar clinical picture. In addition, she suffered reportedly from hemolytic anemia and was treated with blood transfusions and steroids. The third sister (II:2) and the parents were neurologically healthy.

\section{Genetic evaluation}

We performed exome sequencing in both living patients (II:1, II:4, Fig. 1). Only the two heterozygous variants in the ATM gene shown in Table 2 withstood the filtering process as described in materials and methods. Variant 1 is a one base pair deletion leading to an immediate truncation of the large (3056 aa) ATM serine/threonine kinase after amino acid 128. This variant almost certainly results in a loss of function of the ATM protein and has previously been reported as pathogenic (Table 2) [11-13]. Variant 2 is a missense variant that has a CADD score of 23.1 which is nearly identical to variant 1 (23.3) but is classified as benign by PolyPhen-2 and deleterious by MutationTaster (Table 2). Analysis of the data deposited in ClinVar shows that AT-causing variants are relatively evenly distributed over the whole ATM protein, including the region which contains variant 2 (data not shown). Variant 2 has previously been reported as variant of uncertain significance (VUS) or benign because it has also been observed in healthy controls (Table 2) [14]. However, an allele frequency of $1.03 \mathrm{e}-04$ in gnomAD does not argue against causality for a recessive disease. In addition, Coutelier et al. found this variant in the homozygous state in one patient and reported it to be most likely causative [15]. Both variants segregate with disease and are located in trans in the examined family. They are the only variants in ATM and genes causative for related phenotypes which were identified in our exome data using a fairly relaxed filtering approach (CADD score $>15$ and MAF $<1 \%$ and affecting protein sequence or splice sites). Therefore, our data suggest that both variants together cause $\mathrm{AT}$ in this family and that variant 2 should be regarded as causative.
Fig. 2 Ocular telangiectasia. Images show prominent blood vessels over the sclera, labeled by red arrow in a patient \#1 (II.1) and b patient \#2 (II.4) of the Egyptian family
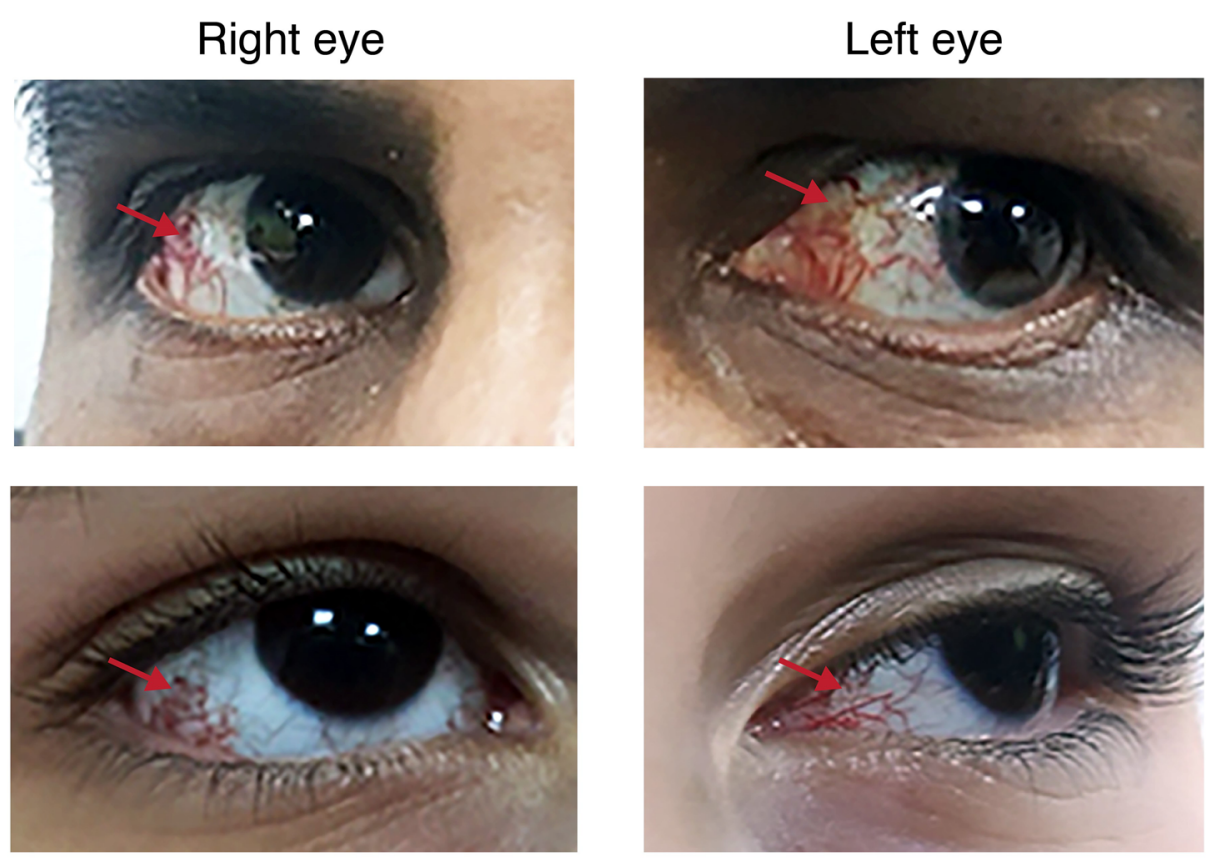
Table 2 Variants in the ATM gene (GRCh38/hg38)

\begin{tabular}{lll}
\hline Genetic finding & Variant \#1 & Variant \#2 \\
\hline Chromosome level & chr11.hg38:g.108235719del & chr11.hg38:g.108301655G>C \\
Genomic level & NC_000011.10:g.108235719del & NC_000011.10:g.108301655G>C \\
Coding sequence level & NM_000051.4:c.381del & NM_000051.4:c.5185G>C \\
Protein level & NM_000051.4(ATM_i001): & NM_000051.4(ATM_i001): \\
& p.(Val128*) & p.(Val1729Leu) \\
CADD (Phred-scaled) & 23.3 & 23.1 \\
MutationTaster (score/class) & Not applicable & $0.972 /$ deleterious \\
PolyPhen-2 HVAR (score/class) & Not applicable & $0.311 /$ benign \\
gnomAD (MAF, nr. of alleles analyzed) & $3.98 \mathrm{e}-06(1 / 251238)$ & $1.03 \mathrm{e}-04$ (29/282530) \\
dbSNP (153 all) & rs587781831 & rs3092907 \\
HGMD (public 01.08.21) & Not listed & not listed \\
ClinVar & Pathogenic & VUS \\
LOVD & VUS, pathogenic & VUS \\
\hline
\end{tabular}

$C A D D$ combined annotation-dependent depletion, $d b S N P$ database of single nucleotide polymorphism, gnomAD genome Aggregation Database, $H G M D$ Human Gene Mutation Database, MAF minor allele frequency, VUS variant of uncertain significance

\section{Discussion}

We show co-segregation and trans-positioning of two putatively causative $A T M$ variants in an Egyptian family with AT. The clinical findings, elevated AFP, and inheritance pattern are typical for AT [2]. Elevated AFP serum levels are also found in ataxia with ocular apraxia types 2 and 4 (AOA2, AOA4). These are differential diagnoses of AT caused by variants in the senataxin (SETX) and the polynucleotide kinase 3'-phosphatase $(P N K P)$ genes [16]. However, patients with AOA2/4 do not exhibit telangiectasia, and our patients did neither carry putatively causative $S E T X$ nor $P N K P$ variants. While variant 1 (NM_000051.4(ATM_i001):p.(Val128*)) has already been regarded as causative, variant 2 (NM_000051.4(ATM_i001):p.(Val1729Leu)) has been classified as VUS or benign. Our data argue that this variant 2 is causative. Segregation, position in trans, low MAF in gnomAD, high CADD score, and the fact that we found no other putatively causative variants for AT or genes implied in the differential diagnoses of AT all point to a pathogenicity of the variant 2 . Additionally, this variant in the homozygous state has previously been reported to be causative in a single AT patient [15]. In summary, we conclude that variant 2 is causative. Limitations of our study are the relatively small size of the family and a lack of functional data.

Acknowledgements We would like to thank the patients and the family for taking part in the present study.

Author contribution All authors contributed to the study conception and design. Material preparation, data collection, and analysis were performed by ASS, GK, TWR, FH, MP, MS, GUH, and SHM. Medical examinations were carried out by ASS, GUH, FH, and GK. The first draft of the manuscript was written by GK, ASS, and TWR, and all authors revised and commented on previous versions of the manuscript. All authors read and approved the final manuscript.

Funding Open Access funding enabled and organized by Projekt DEAL. The present study was supported by the German Academic Exchange Service (DAAD) within the programme Higher Education Dialogue with the Muslim World, project GeneFINDER. MP was supported by the German Research Foundation (FOR-2715, grant He5415/7-1).

Data availability Required data are stored and available upon request.

Code availability Not applicable.

\section{Declarations}

Ethics approval The present study was conducted in accordance with the principles of the Declaration of Helsinki and approved by local Ethics Committee of Mansoura University (RP/42), Egypt and Technical University of Munich (203/15s), Germany.

Consent to participate Written informed consent was obtained for all participants. If the participant was minor or incapable, consent was given by the legal custodian.

Consent for publication All participants gave their consent for publication.

Conflict of interest The authors declare no competing interests.

Open Access This article is licensed under a Creative Commons Attribution 4.0 International License, which permits use, sharing, adaptation, distribution and reproduction in any medium or format, as long as you give appropriate credit to the original author(s) and the source, provide a link to the Creative Commons licence, and indicate if changes were made. The images or other third party material in this article are included in the article's Creative Commons licence, unless indicated otherwise in a credit line to the material. If material is not included in the article's 
Creative Commons licence and your intended use is not permitted by statutory regulation or exceeds the permitted use, you will need to obtain permission directly from the copyright holder. To view a copy of this licence, visit http://creativecommons.org/licenses/by/4.0/.

\section{References}

1. Levy A, Lang AE (2018) Ataxia-telangiectasia: a review of movement disorders, clinical features, and genotype correlations. Mov Disord 33(8):1238-1247. https://doi.org/10.1002/mds.27319

2. Rothblum-Oviatt C, Wright J, Lefton-Greif MA, McGrath-Morrow SA, Crawford TO, Lederman HM (2016) Ataxia telangiectasia: a review. Orphanet J Rare Dis 11(1):159. https://doi.org/10.1186/ s13023-016-0543-7

3. Savitsky K, Bar-Shira A, Gilad S, Rotman G, Ziv Y, Vanagaite L, Tagle DA, Smith S, Uziel T, Sfez S, Ashkenazi M, Pecker I, Frydman M, Harnik R, Patanjali SR, Simmons A, Clines GA, Sartiel A, Gatti RA, Chessa L, Sanal O, Lavin MF, Jaspers NG, Taylor AM, Arlett CF, Miki T, Weissman SM, Lovett M, Collins FS, Shiloh Y (1995) A single ataxia telangiectasia gene with a product similar to PI-3 kinase. Science. 268(5218):1749-1753. https://doi.org/10.1126/science. 7792600

4. Chang X, Wang K (2012) wANNOVAR: annotating genetic variants for personal genomes via the web. J Med Genet 49(7):433436. https://doi.org/10.1136/jmedgenet-2012-100918

5. Kircher M, Witten DM, Jain P, O'Roak BJ, Cooper GM, Shendure J (2014) A general framework for estimating the relative pathogenicity of human genetic variants. Nat Genet 46(3):310-315. https:// doi.org/10.1038/ng.2892

6. Schwarz JM, Cooper DN, Schuelke M, Seelow D (2014) MutationTaster2: mutation prediction for the deep-sequencing age. Nat Methods 11(4):361-362. https://doi.org/10.1038/nmeth. 2890

7. Adzhubei IA, Schmidt S, Peshkin L, Ramensky VE, Gerasimova A, Bork P, Kondrashov AS, Sunyaev SR (2010) A method and server for predicting damaging missense mutations. Nat Methods 7(4):248-249. https://doi.org/10.1038/nmeth0410-248

8. Stenson PD, Mort M, Ball EV, Chapman M, Evans K, Azevedo L, Hayden M, Heywood S, Millar DS, Phillips AD, Cooper DN (2020) The Human Gene Mutation Database $(\operatorname{HGMD}((\mathrm{R})))$ : optimizing its use in a clinical diagnostic or research setting. Hum Genet 139(10):1197-1207. https://doi.org/10.1007/s00439-02002199-3

9. Landrum MJ, Lee JM, Benson M, Brown GR, Chao C, Chitipiralla S, Gu B, Hart J, Hoffman D, Jang W, Karapetyan K, Katz K, Liu C,
Maddipatla Z, Malheiro A, McDaniel K, Ovetsky M, Riley G, Zhou G, Holmes JB, Kattman BL, Maglott DR (2018) ClinVar: improving access to variant interpretations and supporting evidence. Nucleic Acids Res 46(D1):D1062-D10D7. https://doi.org/ 10.1093/nar/gkx1153

10. Fokkema IF, Taschner PE, Schaafsma GC, Celli J, Laros JF, den Dunnen JT (2011) LOVD v.2.0: the next generation in gene variant databases. Hum Mutat 32(5):557-563. https://doi.org/10.1002/ humu. 21438

11. Podralska MJ, Stembalska A, Ślęzak R, Lewandowicz-Uszyńska A, Pietrucha B, Kołtan S, Wigowska-Sowińska J, Pilch J, Mosor M, Ziółkowska-Suchanek I, Dzikiewicz-Krawczyk A, Słomski R (2014) Ten new ATM alterations in Polish patients with ataxiatelangiectasia. Mol Genet Genomic Med 2(6):504-511. https:// doi.org/10.1002/mgg3.98

12. Mitui M, Bernatowska E, Pietrucha B, Piotrowska-Jastrzebska J, Eng L, Nahas S, Teraoka S, Sholty G, Purayidom A, Concannon P, Gatti RA (2005) ATM gene founder haplotypes and associated mutations in Polish families with ataxia-telangiectasia. Ann Hum Genet 69(Pt 6):657-664. https://doi.org/10.1111/j.1529-8817. 2005.00199.x

13. Magliozzi M, Piane M, Torrente I, Sinibaldi L, Rizzo G, Savio C, Lulli P, de Luca A, Dallapiccola B, Chessa L (2006) DHPLC screening of ATM gene in Italian patients affected by ataxia-telangiectasia: fourteen novel ATM mutations. Dis Markers 22(4):257264. https://doi.org/10.1155/2006/740493

14. George Priya Doss C, Rajith B (2012) Computational refinement of functional single nucleotide polymorphisms associated with ATM gene. PLoS One 7(4):e34573. https://doi.org/10.1371/journal.pone. 0034573

15. Coutelier M, Hammer MB, Stevanin G, Monin ML, Davoine CS, Mochel F, Labauge P, Ewenczyk C, Ding J, Gibbs JR, Hannequin D, Melki J, Toutain A, Laugel V, Forlani S, Charles P, Broussolle E, Thobois S, Afenjar A, Anheim M, Calvas P, Castelnovo G, de Broucker T, Vidailhet M, Moulignier A, Ghnassia RT, Tallaksen C, Mignot C, Goizet C, le Ber I, Ollagnon-Roman E, Pouget J, Brice A, Singleton A, Durr A, for the Spastic Paraplegia and Ataxia Network (2018) Efficacy of exome-targeted capture sequencing to detect mutations in known cerebellar ataxia genes. JAMA Neurol 75(5):591-599. https://doi.org/10.1001/jamaneurol.2017.5121

16. Paucar M, Taylor AMR, Hadjivassiliou M, Fogel BL, Svenningsson P (2019) Progressive ataxia with elevated alpha-fetoprotein: diagnostic issues and review of the literature. Tremor Other Hyperkinet Mov (NY) 9. https://doi.org/10.7916/tohm.v0.708

Publisher's note Springer Nature remains neutral with regard to jurisdictional claims in published maps and institutional affiliations. 